OPEN ACCESS

Edited by:

Yanhui Liao,

Zhejiang University School of

Medicine, China

Reviewed by:

Thomas Zandonai,

Miguel Hernández University of

Elche, Spain

Mei Yang,

Shenzhen Mental Health

Centre, China

*Correspondence:

Hongfa Zeng

zenghongfa@szu.edu.cn

Specialty section:

This article was submitted to

Addictive Disorders,

a section of the journal

Frontiers in Psychiatry

Received: 01 December 2021

Accepted: 02 February 2022

Published: 08 March 2022

Citation:

Cui J, LiU F, Liu X, Li R, Chen X and Zeng $H$ (2022) The Impact of Qigong

and Tai Chi Exercise on Drug

Addiction: A Systematic Review and

Meta-Analysis.

Front. Psychiatry 13:826187.

doi: 10.3389/fpsyt.2022.826187

\section{The Impact of Qigong and Tai Chi Exercise on Drug Addiction: A Systematic Review and Meta-Analysis}

\author{
Jiabao Cui, Fang Liu, Xuan Liu, Ru Li, Xiaorong Chen and Hongfa Zeng* \\ Faculty of Physical Education, Shenzhen University, Shenzhen, China
}

Background: Previous preliminary studies have found that qigong exercises produced significant effects in healthy people and in various clinical populations. The purpose of this study was to systematically review the effects of qigong and tai chi exercise on individuals with drug addiction.

Methods: A systematic search of seven English databases and three Chinese databases was conducted to identify randomized controlled trials (RCTs) and non-randomized comparative studies (NRS) assessing the effects of qigong and tai chi on drug addiction. Study quality was assessed using the Checklist for the Evaluation of Non-Pharmaceutical Trial Reports (CLEAR-NPT).

Results: Two RCTs and nine NRS studies were included in this study, including a total of 1072 patients with drug addiction (age range, 27-43 years). The results showed that qigong and tai chi exercise had a significant overall effect on depression ( $S M D=-0.353$, $95 \% \mathrm{Cl}[-0.548,-0.159])$, anxiety $(\mathrm{SMD}=-0.541,95 \% \mathrm{Cl}[-0.818,-0.264])$, quality of life (SMD $=0.673,95 \% \mathrm{Cl}[0.438,0.907])$, and sleep quality (SMD $=-0.373,95 \% \mathrm{Cl}$ $[-0.631,-0.116])$. The subgroup analysis found that qigong outperformed tai chi on the improving depression, anxiety, and sleep quality.

Conclusion: Existing studies suggest that qigong and tai chi are effective at improving depression, anxiety, and quality of life in drug users; however, the evidence from rigorous randomized controlled group trials is lacking.

Keywords: mind-body exercise, addiction, craving, mental health, meta-analysis

\section{INTRODUCTION}

The World Drug Report 2020 shows that $\sim 35$ million people worldwide are addicted to drugs (1). However, due to inadequate prevention and limited treatment resources, only 1 in 7 patients currently have access to treatment (1). Drug addiction is a chronic relapsing mental illness that afflicts millions of people $(2,3)$ and is closely related to the physical health of the patients. Drug addiction substantially increases the risk of suffering from various types of disease, including infectious illness, cancer, and chronic diseases $(4,5)$. As the number of detoxification sessions and length of drug use increase, the mental health of patients tends to decrease (6), and their chances of developing psychiatric disorders (e.g., major depression, bipolar disorder, specific phobias, antisocial personality disorder, and borderline personality disorder) increase substantially $(7,8)$. 
In addition to the health problems, drug addiction causes loss of productivity, homelessness, and progressive violence, leading patients to be more prone to crime and other behaviors that endanger public safety (9-11). Currently, physiological detoxification methods (e.g., pharmacological interventions) are the main methods used by the international community to handle drug addiction (12-15). Although it is the most effective and direct method for controlling patients, the side effects are also very evident and lead to negative effects on patients' physical and mental health (16-19). Therefore, it is particularly important and urgent to find a safe and effective way to implement drug rehabilitation (20-22).

Previous studies have highlighted the benefits of exercise on the development of physical and mental health in healthy and clinical populations $(23,24)$. Some studies have suggested that exercise can be regarded as an adjunctive treatment for smoking cessation, alcoholism, and substance abuse (2327). In addition to conventional forms of physical exercise, Qigong and tai chi have long been adopted for use by the National Institutes of Health as an alternative treatment of several chronic diseases $(28,29)$. Both Qigong and tai chi originated from ancient martial arts, which are based on four principles proposed by Larkey et al. (30). They include specific movement patterns or body postures, deep diaphragmatic breathing, a meditative state of mind, and a relaxed state of mind. There are several previous reviews showing that long-term qigong or tai chi exercise contributes to physical and mental health $(22,31-34)$. However, the underlying mechanism regarding the benefits of qigong and tai chi remains unconfirmed. One of the most accepted neurophysiological mechanism is that mindful concentration emphasized by qigong and tai chi exercise improves well-being by regulating the autonomic nervous system, specifically by upregulating the parasympathetic nervous system (35). Another assumption proposed that qigong and tai chi could benefit emotion regulation by mediating of the hypothalamic-pituitaryadrenal (HPA) axis (e.g., reduced saliva cortisol level) (35). One previous meta-analysis showed that moderate- to high-intensity mind-body exercises can be effective in increasing withdrawal rates from drug addiction, alleviating anxiety and depression, and serving as effective and sustained treatments for drug addiction disorders $(22,33,34)$.

Qigong and tai chi have advantages over traditional methods of physiological detoxification because they are easy to learn and safe (36-40). Although qigong and tai chi detoxification have attracted the attention of researchers, most existing studies focused only on limited aspects, including the alleviation of depression (15, 41-44), anxiety $(15,41-43,45)$, withdrawal symptoms (46), cocaine cravings (43), and improving quality of life $(47-49)$, as well as sleep quality $(41,44)$. However, the effects remain unclear due to differences in study designs and the interventions performed $(43,50)$. Several previous reviews focus only on improvements in patients' anxiety and depression during drug withdrawal $(43,50)$, and limited to investigate the detoxification process, such as the correlation between patients' physical and mental health and the six indicators mentioned above, including withdrawal symptoms, quality of life, and cravings. Therefore, it is necessary to quantitatively analyze the effects of qigong and tai chi on drug addiction.

\section{METHODS}

\section{Literature Search}

The literature search was conducted by two researchers, both of whom used an independent double-blind approach while searching the Medline (via PubMed), EMbase (via Ovid), PsychINFO (via Ovid), Eric (via EBSCOhost), SPORTDiscus (via EBSCOhost), CINAHL (via EBSCOhost), the Cochrane Central Register of Controlled Trials (CENTRAL), the China National Knowledge Infrastructure (CNKI), and Wanfang Data databases. In addition, a combined search for published papers related to the effects of qigong and tai chi on drug addiction was conducted on the Chinese Journal of Science (VIP) database from its date of inception to June 2020. This was conducted using Chinese search terms such as "fitness qigong," "qigong," "drug addiction," "physical and mental rehabilitation," "anxiety," "depression." A combined search was also conducted using English search terms such as "qigong," "qi gong," "heroin," "morphine," "recovery," "treatment," and so on. The search was limited to "human" as the subject, "English" and "Chinese article with an English abstract" as the language, and 'peer-reviewed journal' as the literature type.

\section{Inclusion and Exclusion Criteria Types of Studies}

The included studies were randomized controlled trials (RCTs) or non-randomized comparative studies (NRS) published in peerreviewed journals. Studies were considered RCTs if the study used and described a randomization method explicitly at the time of participant randomization (e.g., use of computerized random number generators, coin flips, or lotteries). Similarly, studies were considered NRSs if they were generated only by pseudorandom or non-random methods (e.g., use of date of birth, date of admission, participant preferences, or intervention usability). Studies were excluded if they were observational studies (e.g., cross-sectional, case control), reviews, conference abstracts, and book chapters that did not involve any comparisons of outcomes between groups.

\section{Types of Participants}

Participants included in the studies were patients aged 18 years and older with illicit drug abuse or dependence (based on DSM$3 / 4 / 5$ as the diagnosis). Patients with drug abuse or dependence who also had alcohol or nicotine dependence or severe specific conditions (e.g., cancer, asthma) were excluded.

\section{Types of Interventions}

Studies in which the experimental group used any type of tai chi or qigong as an intervention and the control group used treatment as usual (TAU) or other types of interventions (e.g., medications) were included in the analysis. Studies in which the experimental group used tai chi or qigong with other interventions superimposed and studies in which static qigong (meditation or positive thinking) were excluded. 


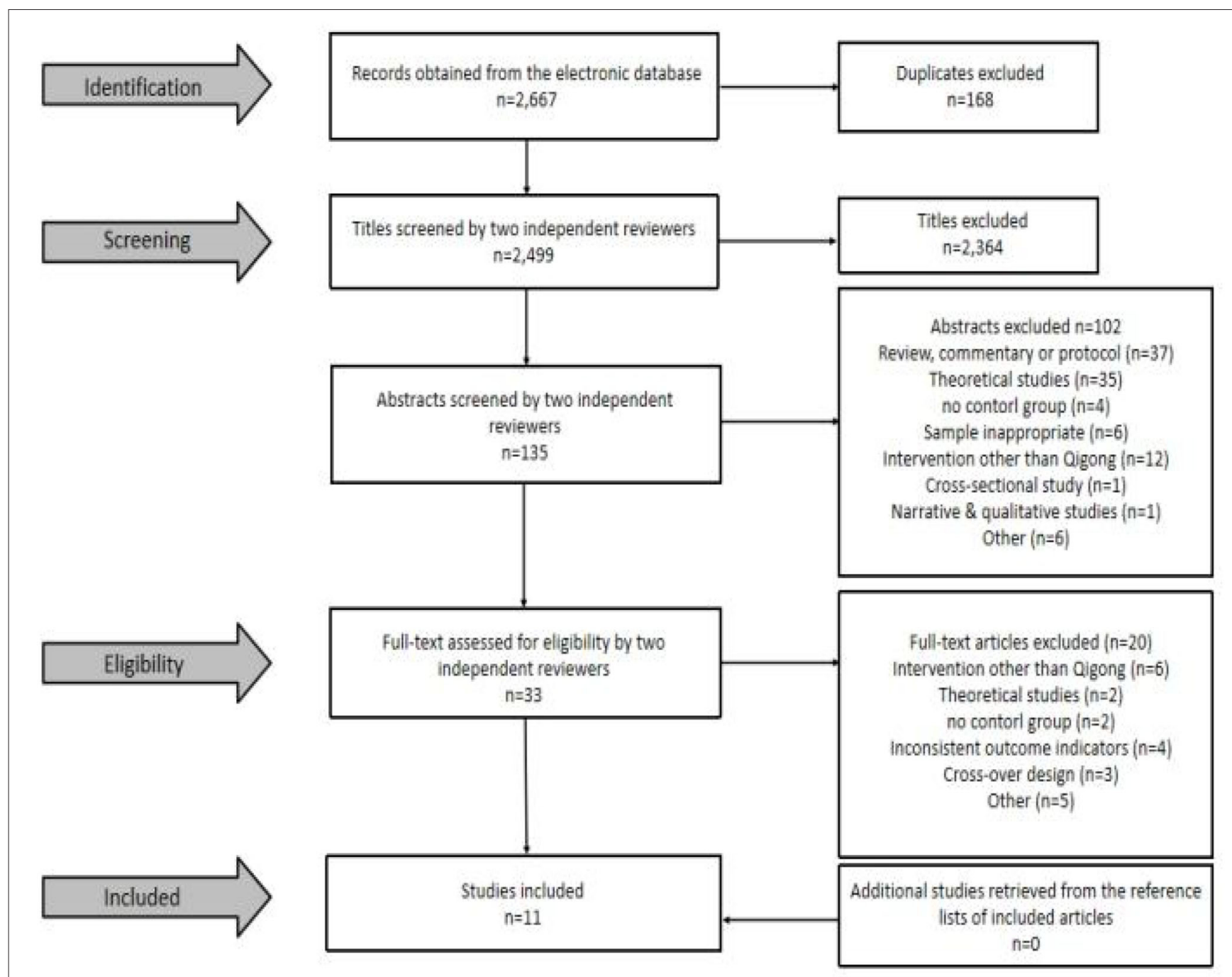

FIGURE 1 | Selection process for included studies.

\section{Literature Screening and Data Extraction}

Literature screening was performed by two researchers (JC, FL) based on the inclusion and exclusion criteria. Judgment of exclusion was made by reading the titles and abstracts, and fulltext downloading was performed after obtaining literature that largely met the inclusion criteria. Final judgment of inclusion was made after reading the full text in detail. If the opinions of the two researchers did not align, the final decision was made by a third researcher (RL) after a group consultation. Finally, one researcher (XL) looked for potentially missing articles from a review of the literature related to the effects of tai chi and qigong on addiction (Figure 1). The consistency of literature screening was tested by calculating the Kappa $(\mathrm{K})$ coefficient, with $\mathrm{K}>0.75$ indicating good consistency, $0.4 \leq \mathrm{K} \leq 0.75$ indicating fair consistency, and $\mathrm{K}<0.4$ indicating poor consistency (51).

All relevant data were extracted from the screened literature, including the first author, year of publication, study population, sample size, gender, age, intervention period, intervention protocol, and outcome indicators. For literature with missing or unclear of data, we contacted the authors of the article to obtain any relevant information. If there was no response after three emails, we classified the study information as "Unsure" and rated it as "U" (Table 1).

\section{Quality Assessment}

The methodological quality of included studies were independently assessed by two researchers (JC, FL) based on the criteria of a Checklist to Evaluate a Report of a Non-pharmacological Trial (CLEAT-NPT) (52). The quality assessment followed criteria including randomization, concealed allocation, the availability of intervention details, appropriate experience of care providers, participant compliance, participant/caregiver blinding, blinding of outcome assessors, equality of follow-up schedules between groups, and intentionto-treat principles. The quality of the included studies was rated by calculating a quality rating index (0-100\%) (53). The quality 
TABLE 1 | Characteristics of the included studies on the impact of qigong and tai chi exercise on drug addiction.

\begin{tabular}{|c|c|c|c|c|c|c|c|c|}
\hline References & $\begin{array}{l}\text { Study design; } \\
\text { location }\end{array}$ & $\begin{array}{l}\text { Study } \\
\text { participants }\end{array}$ & $\begin{array}{l}\text { Sample size } \\
\text { (Mean age } \pm \text { SD) }\end{array}$ & Intervention & Control & Duration & $\begin{array}{l}\text { Outcome } \\
\text { measures }\end{array}$ & Results \\
\hline Li et al. (15) & $\begin{array}{l}\text { NRS, Yunnan, } \\
\text { China }\end{array}$ & $\begin{array}{l}\text { Females with drug } \\
\text { dependence on } \\
\text { heroin }\end{array}$ & $\begin{array}{l}\text { Exp: } 36 \text { (30.7 } \\
\pm 6.3) \text { Con: } 34 \\
(30.7 \pm 6.3)\end{array}$ & $\begin{array}{l}\text { Qigong-Tai Chi } \\
\text { ( } 1 \mathrm{~h} \text {, once every } \\
\text { two days) }\end{array}$ & TAU & $24 w k$ & HRSD & $p=0.049$ \\
\hline Smelson et al. (43) & $\mathrm{RCT}, ? ?$ & $\begin{array}{l}\text { Individuals with } \\
\text { dependence on } \\
\text { cocaine (sex } \\
\text { unreported) }\end{array}$ & $\begin{array}{l}\text { Exp: } 45 \text { (36.0 } \\
\pm 9.4) \text { Con: } 41 \\
(40.4 \pm 11.9)\end{array}$ & $\begin{array}{l}\text { Qigong (15 min, } \\
2-3 \text { times per } \\
\text { week, once every } \\
\text { two days) }\end{array}$ & TAU & $2 w k$ & $\begin{array}{l}\text { (1) } C C Q \\
\text { (2) BDI } \\
\text { (3) STAI }\end{array}$ & $\begin{array}{l}\text { (1) } p=0.06 \\
\text { (2) } p<0.05 \\
\text { (3) } p>0.05\end{array}$ \\
\hline Zhu et al. (44) & $\begin{array}{l}\text { RCT, Shanghai, } \\
\text { China }\end{array}$ & $\begin{array}{l}\text { Females with } \\
\text { dependence on } \\
\text { amphetamine-type } \\
\text { stimulant }\end{array}$ & $\begin{array}{l}\text { Exp: } 42 \text { (33.74 } \\
\pm 7.11) \text { Con: } 38 \\
(37.76 \pm 9.85)\end{array}$ & $\begin{array}{l}\text { Qigong-Tai Chi } \\
24 \text {-form ( } 1 \mathrm{~h} \text {, five } \\
\text { sessions per week } \\
\text { for the first } 3 \\
\text { months, and three } \\
\text { times per week for } \\
\text { next } 3 \text { months) }\end{array}$ & TAU & $24 w k$ & $\begin{array}{l}\text { (1) PSQI } \\
\text { (2) SDS }\end{array}$ & $\begin{array}{l}\text { (1) } p=0.027 \\
\text { (2) } p>0.05\end{array}$ \\
\hline Geng et al. (42) & $\begin{array}{l}\text { NRS, Shanghai, } \\
\text { China }\end{array}$ & $\begin{array}{l}\text { Females with } \\
\text { dependence on } \\
\text { synthetic drugs }\end{array}$ & $\begin{array}{l}\text { Exp: } 30 \\
(34.0 \pm 7.0) \text { Con: } \\
30(38.0 \pm 5.0)\end{array}$ & $\begin{array}{l}\text { Qigong-Tai Chi } \\
24 \text {-form } \\
\text { (45 min, } 5 \text { times } \\
\text { per week) }\end{array}$ & TAU & 12 wk & $\begin{array}{l}\text { (1) SCL-90 } \\
\text { (Depression) } \\
\text { (2) } \\
\text { SCL-90 (Anxiety) }\end{array}$ & $\begin{array}{l}\text { (1) } p>0.05 \\
\text { (2) } p>0.05\end{array}$ \\
\hline Fu et al. (41) & NRS, Anhui, China & $\begin{array}{l}\text { Females with drug } \\
\text { dependence on } \\
\text { heroin, } \\
\text { methamphetamine, } \\
\text { k powder, and } \\
\text { ecstasy }\end{array}$ & $\begin{array}{l}\text { Exp: } \\
100(28.3 \pm 7.83) \\
\text { Con: } \\
100(27.99 \pm 8.17)\end{array}$ & $\begin{array}{l}\text { Qigong-Wu Qin Xi } \\
\text { ( } 30 \text { min, once per } \\
\text { day) }\end{array}$ & No treatment & $20 w k$ & $\begin{array}{l}\text { (1) SAS } \\
\text { (2) SDS } \\
\text { (3) PSQI }\end{array}$ & $\begin{array}{l}\text { (1) } p=0.000 \\
\text { (2) } p=0.003 \\
\text { (3) } p=0.000\end{array}$ \\
\hline Huang et al. (45) & $\begin{array}{l}\text { NRS, Zhuhai, } \\
\text { China }\end{array}$ & $\begin{array}{l}\text { Individuals with } \\
\text { dependence on } \\
\text { heroin ( } M=68, F \\
=32 \text { ) }\end{array}$ & $\begin{array}{l}\text { Exp: } \\
50(35.26 \pm 12.22) \\
\text { Con: } \\
50(35.21 \pm 12.12)\end{array}$ & $\begin{array}{l}\text { Qigong-Ba Duan } \\
\text { Jin ( } 30 \mathrm{~min} \text {, twice } \\
\text { a day) }\end{array}$ & Medication & $20 w k$ & SAS & $p<0.05$ \\
\hline Li et al. (47) & $\begin{array}{l}\text { NRS, Gansu, } \\
\text { China }\end{array}$ & $\begin{array}{l}\text { Individuals with } \\
\text { dependence on } \\
\text { opioid } \\
\text { dependence ( } M= \\
160, F=40 \text { ) }\end{array}$ & $\begin{array}{l}\text { Exp: } 100 \\
(41.47 \pm 16.65) \\
\text { Con: } 100 \\
(40.18 \pm 11.83)\end{array}$ & $\begin{array}{l}\text { Qigong-Dao Yin } \\
\text { ( } 1 \mathrm{~h} \text {, once } \\
\text { every days) }\end{array}$ & $\begin{array}{l}\text { Regular physical } \\
\text { exercise }\end{array}$ & 12 wk & QOL-DA & $p<0.05$ \\
\hline Zhu et al. (48) & $\begin{array}{l}\text { NRS, Shanghai, } \\
\text { China }\end{array}$ & $\begin{array}{l}\text { Females with } \\
\text { dependence on } \\
\text { synthetic drugs }\end{array}$ & $\begin{array}{l}\text { Exp: } 43 \text { (34.0 } \\
\pm 7.0) \text { Con: } 39 \\
(38.0 \pm 10.0)\end{array}$ & $\begin{array}{l}\text { Qigong-Tai Chi } \\
\text { ( } 1 \mathrm{~h}, 5 \text { times per } \\
\text { week for the first } 3 \\
\text { months, and } 3 \\
\text { times per week for } \\
\text { next } 3 \text { months) }\end{array}$ & TAU & 24 wk & QOL-DA & $p<0.01$ \\
\hline
\end{tabular}




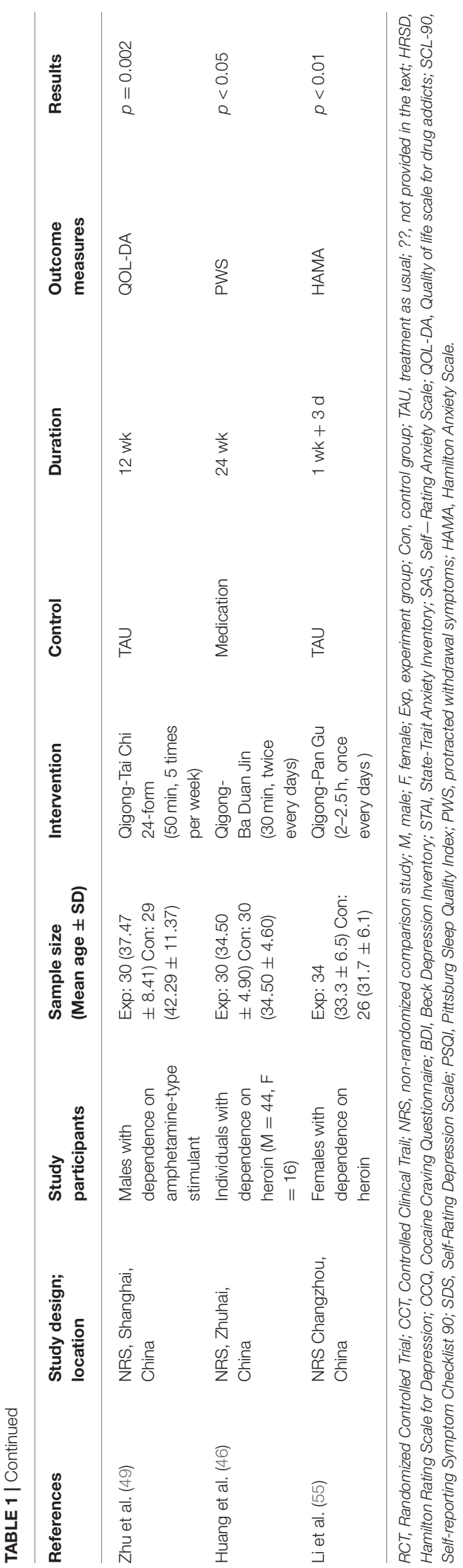

evaluation can be divided into two parts: [1] the quality of each study (cross-sectional) in terms of individual study units, based on the 10 criteria mentioned above, and [2] the quality of the included studies (as a whole) in terms of each individual criterion. Values below $60 \%$ were of substandard quality, those between 60 and $80 \%$ were considered to be of fair quality, and those above $80 \%$ were considered to be of good quality. Each criterion was indicated as met $(\mathrm{Y})$ if it fully met the above criteria, not met $(\mathrm{N})$ if it did not, or uncertain $(\mathrm{U})$ if the criteria were not mentioned in the text, if the report was unclear, or if there was no response from the authors after multiple email contacts.

\section{Data Analysis}

A meta-analysis was conducted to explore the effects of qigong and tai chi on addiction. The pre- and post-intervention measurements of the experimental and control groups were entered into the Comprehensive Meta-Analysis (CMA) V2, and the results of the total effects from random effects (overall) were selected to evaluate the effects of qigong and tai chi on addiction. In addition, mixed effects analysis results were selected to evaluate the differences of between groups (qigong vs. tai chi). The results of the data analysis are subject to the possibility of heterogeneity due to differences in the intervention period, the characteristics of the participants, and the scales used in the included studies. To account for potential heterogeneity, random effect (standardized mean difference [SMD], 95\% CI) models were used throughout the data synthesis and analysis process. $I^{2}=0$ indicated no heterogeneity among studies; $I^{2}=$ $25-50 \%$ indicated low heterogeneity among studies; $I^{2}=50-75 \%$ indicated moderate heterogeneity among studies; and $\mathrm{I}^{2}>75 \%$ indicated high heterogeneity among studies (54).

\section{RESULTS}

\section{Literature Screening}

Figure 1 summarizes the process and results of the literature screening. In total, 2,667 articles were retrieved by the search method mentioned above, 168 duplicates were excluded, and title screening $(n=2,499)$ was then performed to exclude 2,364 articles that did not meet the criteria. Subsequently, the remaining articles $(n=135)$ were screened for abstracts, and 102 articles that did not meet the criteria were excluded. The remaining articles $(n=33)$ were then screened in full to exclude 20 studies that did not meet the criteria, resulting in the inclusion of 13 studies that met the criteria (randomized controlled trials $=12$, quasi-experiments $=1$ ). Kappa $(\mathrm{K})$ coefficients were calculated for the literature that was screened independently by the two researchers, and the results showed that the Kappa coefficients for both the abstract screening $(K=0.85)$ and full-text screening $(K=$ 0.84 ) were $>0.75$, indicating that the degree of consistency between the two researchers' literature screening results was good.

\section{Characteristics of Included Studies}

Table 1 shows the characteristics of the included studies. The included studies five $(15,43,44,49,55)$ in English and six $(41,42$, 
45-48) in Chinese were all published in peer-reviewed journals. Of these, two studies $(46,47)$ were RCTs and nine $(15,41,42,44-$ $48,55)$ were NRSs. Ten studies were conducted in China $(15,41-$ $48,55)$, and one study did not mention the location of the trial in the text (43). The drug addicted participants included heroin, methamphetamine, amphetamine-type stimulants, and synthetic drug dependents, with sample sizes ranging from 59 to 200, for a total of 1,072 subjects (546 in the intervention group and 527 in the control group); six studies $(15,41,42,44,48,55)$ had all female participants, and one study (49) recruited all male participants.

The interventions in the experimental group were qigong exercises (e.g., Wu Qin Xi, Ba Duan Jin, Dao Yin, Pan Gu qigong) or tai chi (e.g., 24-form tai chi). The interventions in the control group were treatment as usual, medication, daily physical exercise, and no treatment. All studies considered only the immediate effects and impact of qigong exercise in drug addicts, with few studies providing follow-up measurements. In terms of outcome indicator measures, five studies $(15,41-44)$ measured depression variables by self-reported questionnaires (e.g., HRSD, BDI, SCL-90, SDS), and five studies $(41-43,45,55)$ measured anxiety variables by various questionnaires (e.g., SAMA, STAI, SAS, SCL-90). Three studies (47-49) focused on the quality of life (e.g., QOL-DA), two studies $(41,44)$ used subjectively-measured sleep quality (e.g., PSQI).

\section{Quality Evaluation}

Table 2 shows the results of the quality evaluation of the studies included. Only two studies $(18 \%)(43,44)$ used a random number table or computer-generated random numbers for random assignment of subjects. Only two studies (18\%) $(42,48)$ implemented allocation concealment. Ten studies $(91 \%)$ $(15,41-45,47-49,55)$ provided details of each randomized grouping intervention. Only four studies (36\%) (42, 43, 47, 48) had details on the experience or skills of the person implementing the intervention that were appropriate. Only one study $(9 \%)$ ( $\mathrm{Li}, 2018)$ provided a quantitative assessment of subject (e.g., patients) compliance. Nine studies (15, 41-47, 49, 55) showed no significant difference in the number of subjects who dropped out and were lost to follow-up in the experimental and control groups. Similarly, although only one study (9\%) (43) implemented adequate blinding of intervenors, nine studies $(15,42-49)$ had intervenors who provided consistent alternative treatment and care for each randomized subgroup. Six studies (86\%) $(15,42-44,48,49)$ were adequately blinded to those assessing the outcome variable. Nine studies (82\%) (15, 41$45,47-49$ ) implemented fully parallel intervention plans in the experimental and control groups. Looking at the individual studies, the overall quality was poor, with only one study (43) classified as good quality, meeting $83 \%$ of the evaluation criteria; two studies $(42,47)$ were of fair quality, meeting 64 and $69 \%$ of the evaluation criteria respectively; eight studies $[(15,44,48,49,55)$; Huang and $\mathrm{Xu}, 2015$; Fu, 2016; Huang and $\mathrm{Wu}, 2017]$ were of substandard quality, in which only 33 , $50,46,50,45,50,33$, and $57 \%$ of the evaluation criteria were met, respectively.

\section{Effects of Qigong and Tai Chi on Depressive Symptoms}

Five of the included studies examined the effects of qigong or tai chi exercise on depression $(15,41-44)$. Overall, qigong and tai chi had a significant effect on alleviating depression in patients with drug addiction $(\mathrm{SMD}=-0.353,95 \% \mathrm{CI}[-0.548,-0.159], p$ $=0.000)$, with high homogeneity $\left(I^{2}=0\right)$. We also implemented the subgroup analyses to compare the effects of qigong and tai chi on depressive symptoms, indicating a significant effect of qigong on depression (SMD $=-0.434,95 \% \mathrm{CI}[-0.668,-0.199]$ ) with high homogeneity $\left(I^{2}=0\right)$; but non-significant effect of tai chi exercise on the improvement of depressive symptoms (SMD = $-0.175,95 \%$ CI $[-0.525,0.175]$ ) (Figure 2A).

\section{Effects of Qigong and Tai Chi on Anxiety Symptoms}

Five of the included studies examined the effects of qigong or tai chi exercise on anxiety symptoms $(41-43,45,55)$. In total, qigong and tai chi exercise had a significant overall effect on alleviating anxiety symptoms in patients with drug addiction $(\mathrm{SMD}=-0.541,95 \% \mathrm{CI}[-0.818,-0.264], p=0.000)$, with moderate heterogeneity $\left(I^{2}=52.88\right)$. The subgroup analysis showed that qigong exercise had a significant effect on decreasing anxiety (SMD $=-0.629,95 \% \mathrm{CI}[-0.955,-0.302])$ with high heterogeneity $\left(I^{2}=60.58\right)$. However, tai chi exercise reported a non-significant effect on anxiety (SMD $=-0.317,95 \% \mathrm{CI}$ $[-0.840,0.207])$ with high homogeneity $\left(I^{2}=0\right)$ (Figure $\left.2 \mathbf{B}\right)$.

\section{Impact of Qigong and Tai Chi on Quality of Life}

Three of the included studies examined the effect of qigong or tai chi exercise on quality of life (47-49). The overall effects showed that qigong and tai chi had a significant effect on improving the quality of life of patients with drug addiction (SMD = $0.673,95 \%$ CI $[0.438,0.907])$, with high homogeneity $\left(I^{2}=0\right)$. Among the studies, one study (47) examined the effect of qigong exercise on quality of life in drug addicts $(\mathrm{SMD}=0.750,95 \% \mathrm{CI}$ $[0.463,1.036])$. Two studies $(48,49)$ examined the effect of tai chi exercise on the quality of life of drug addicts (SMD = $0.517,95 \%$ CI $[0.109,0.925])$, with high homogeneity $\left(I^{2}=0\right)$ (Figure 2C).

\section{Effects of Qigong and Tai Chi on Sleep Quality}

Two of the included studies examined the effect of qigong or tai chi exercise on sleep quality (PSQI) $(41,44)$. The results showed that qigong and tai chi exercise had a significant overall effect on relieving anxiety symptoms in patients with drug addiction (SMD $=-0.373,95 \% \mathrm{CI}[-0.631,-0.116])$, with low heterogeneity $\left(I^{2}\right.$ $=8.998)$ (Figure 2D).

\section{DISCUSSION}

This review summarizes the effects of qigong and tai chi exercise on patients with drug addiction. Overall, qigong and tai chi 
TABLE 2 | Critical appraisal of included studies.

\begin{tabular}{|c|c|c|c|c|c|c|c|c|c|c|c|c|}
\hline Criteria & Li et al. (15) & $\begin{array}{l}\text { Smelson } \\
\text { et al. } \\
(43)\end{array}$ & $\begin{array}{l}\text { Zhu et } \\
\text { al. (44) }\end{array}$ & $\begin{array}{l}\text { Geng et } \\
\text { al. (42) }\end{array}$ & $\begin{array}{l}\text { Fu et al. } \\
\text { (41) }\end{array}$ & $\begin{array}{l}\text { Huang } \\
\text { et al. } \\
(45)\end{array}$ & $\begin{array}{l}\text { Li et al. } \\
\text { (47) }\end{array}$ & $\begin{array}{l}\text { Zhu et } \\
\text { al. (48) }\end{array}$ & $\begin{array}{l}\text { Zhu et } \\
\text { al. (49) }\end{array}$ & $\begin{array}{l}\text { Huang } \\
\text { et al. } \\
(46)\end{array}$ & $\begin{array}{l}\text { Li et al. } \\
\text { (55) }\end{array}$ & $\begin{array}{l}\text { Score }^{a} \\
(\% Y)\end{array}$ \\
\hline $\begin{array}{l}\text { 1. Was the generation } \\
\text { of allocation } \\
\text { adequate? }\end{array}$ & $U$ & Y & $Y$ & $N$ & U & U & U & N & $N$ & U & U & $18 \%$ \\
\hline $\begin{array}{l}\text { 2. Was the treatment } \\
\text { allocation } \\
\text { concealed? }\end{array}$ & U & U & $\mathrm{N}$ & Y & U & U & N & Y & $N$ & $U$ & U & $18 \%$ \\
\hline $\begin{array}{l}\text { 3. Were details of the } \\
\text { intervention } \\
\text { administered to } \\
\text { each group made } \\
\text { available? }\end{array}$ & Y & Y & $Y$ & Y & Y & $Y$ & Y & Y & Y & U & Y & $91 \%$ \\
\hline $\begin{array}{l}\text { 4. Were care providers' } \\
\text { experience or skills } \\
\text { in each arm } \\
\text { appropriate? }\end{array}$ & $U$ & Y & U & Y & U & U & Y & Y & $U$ & $U$ & U & $36 \%$ \\
\hline $\begin{array}{l}\text { 5. Was participant (i.e., } \\
\text { patients) adherence } \\
\text { assessed } \\
\text { quantitatively? }\end{array}$ & U & U & U & $N$ & U & U & Y & $\mathrm{N}$ & $U$ & U & u & $9 \%$ \\
\hline $\begin{array}{l}\text { 6. Were participants } \\
\text { (i.e., patients) } \\
\text { adequately blinded? } \\
\text { if no, go to point } 6.1 \\
\text { and } 6.2\end{array}$ & $\mathrm{~N}$ & Y & $N$ & $N$ & $N$ & N & N & $N$ & $\mathrm{~N}$ & $\mathrm{~N}$ & N & $9 \%$ \\
\hline $\begin{array}{l}\text { 6.1. Were other } \\
\text { treatments and } \\
\text { care (i.e. } \\
\text { co-interventions) } \\
\text { the same in each } \\
\text { randomized } \\
\text { group? }\end{array}$ & Y & N/A & $\mathrm{Y}$ & Y & N/A & Y & Y & Y & $\mathrm{Y}$ & Y & u & $89 \%$ \\
\hline $\begin{array}{l}\text { 6.2. Were withdrawals } \\
\text { and lost to follow } \\
\text { up the same in } \\
\text { each randomized } \\
\text { group? }\end{array}$ & Y & N/A & Y & Y & Y & Y & $Y$ & $N$ & Y & Y & Y & $90 \%$ \\
\hline $\begin{array}{l}\text { 7. Were care providers } \\
\text { for the participants } \\
\text { adequately blinded? } \\
\text { if no, go to point } 7.1 \\
\text { and } 7.2\end{array}$ & $U$ & Y & U & $\mathrm{N}$ & $\mathrm{N}$ & N & N & $N$ & $U$ & $N$ & U & $9 \%$ \\
\hline
\end{tabular}


TABLE 2 | Continued

\begin{tabular}{|c|c|c|c|c|c|c|c|c|c|c|c|c|}
\hline Criteria & Li et al. (15) & $\begin{array}{l}\text { Smelson } \\
\text { et al. } \\
\text { (43) }\end{array}$ & $\begin{array}{l}\text { Zhu et } \\
\text { al. (44) }\end{array}$ & $\begin{array}{l}\text { Geng et } \\
\text { al. (42) }\end{array}$ & $\begin{array}{l}\text { Fu et al. } \\
\text { (41) }\end{array}$ & $\begin{array}{l}\text { Huang } \\
\text { et al. } \\
\text { (45) }\end{array}$ & $\begin{array}{l}\text { Li et al. } \\
\text { (47) }\end{array}$ & $\begin{array}{l}\text { Zhu et } \\
\text { al. (48) }\end{array}$ & $\begin{array}{l}\text { Zhu et } \\
\text { al. (49) }\end{array}$ & $\begin{array}{l}\text { Huang } \\
\text { et al. } \\
\text { (46) }\end{array}$ & $\begin{array}{l}\text { Li et al. } \\
\text { (55) }\end{array}$ & $\begin{array}{l}\text { Score }^{a} \\
(\% Y)\end{array}$ \\
\hline $\begin{array}{l}\text { 7.1. Were other } \\
\text { treatments and } \\
\text { care (i.e. } \\
\text { co-interventions) } \\
\text { the same in each } \\
\text { randomized } \\
\text { group? }\end{array}$ & Y & Y & Y & Y & $N / A$ & Y & Y & Y & Y & Y & N/A & $100 \%$ \\
\hline $\begin{array}{l}\text { 7.2. Were withdrawals } \\
\text { and } \\
\text { lost-to-follow-up } \\
\text { the same in each } \\
\text { randomized } \\
\text { group? }\end{array}$ & Y & Y & Y & Y & Y & Y & Y & $\mathrm{N}$ & Y & Y & Y & $91 \%$ \\
\hline $\begin{array}{l}\text { 8. Were outcome } \\
\text { assessors } \\
\text { adequately blinded } \\
\text { to assess the } \\
\text { primary outcomes? } \\
\text { If no, go to } 8.1\end{array}$ & Y & Y & Y & $Y$ & $\mathrm{~N} / \mathrm{A}$ & N/A & $\mathrm{N} / \mathrm{A}$ & Y & Y & U & $\mathrm{N} / \mathrm{A}$ & $86 \%$ \\
\hline $\begin{array}{l}\text { 8.1. If outcome } \\
\text { assessors were } \\
\text { not adequately } \\
\text { blinded, were } \\
\text { specific methods } \\
\text { used to avoid } \\
\text { ascertainment } \\
\text { bias? }\end{array}$ & $\mathrm{N} / \mathrm{A}$ & N/A & $\mathrm{N} / \mathrm{A}$ & $\mathrm{N} / \mathrm{A}$ & $\mathrm{N} / \mathrm{A}$ & $\mathrm{N} / \mathrm{A}$ & N/A & N/A & $\mathrm{N} / \mathrm{A}$ & $U$ & $\mathrm{~N} / \mathrm{A}$ & $0 \%$ \\
\hline $\begin{array}{l}\text { 9. Was the follow-up } \\
\text { schedule the same } \\
\text { in each group? } \\
\text { (parallel design) }\end{array}$ & Y & Y & Y & Y & Y & Y & Y & Y & Y & $U$ & U & $82 \%$ \\
\hline $\begin{array}{l}\text { 10. Were the main } \\
\text { outcomes } \\
\text { analyzed } \\
\text { according to the } \\
\text { intention-to-treat } \\
\text { principle? }\end{array}$ & $\mathrm{N}$ & Y & $\mathrm{N}$ & $\mathrm{N}$ & Y & $N$ & Y & $\mathrm{N}$ & N & Y & Y & $45 \%$ \\
\hline Score $^{b}(\%$ Y) & $50 \%$ & $83 \%$ & $57 \%$ & $64 \%$ & $45 \%$ & $46 \%$ & $69 \%$ & $50 \%$ & $50 \%$ & $33 \%$ & $33 \%$ & \\
\hline
\end{tabular}

Y, yes; N, no; N/A, not appropriate (not included in the score); U, unable to determine; Scorea (\% Y), percentage of the number of studies scoring "Yes" for each criterion; Score ${ }^{b} \%$ Y), percentage of the number of "Yes" scoring for each study. 
A

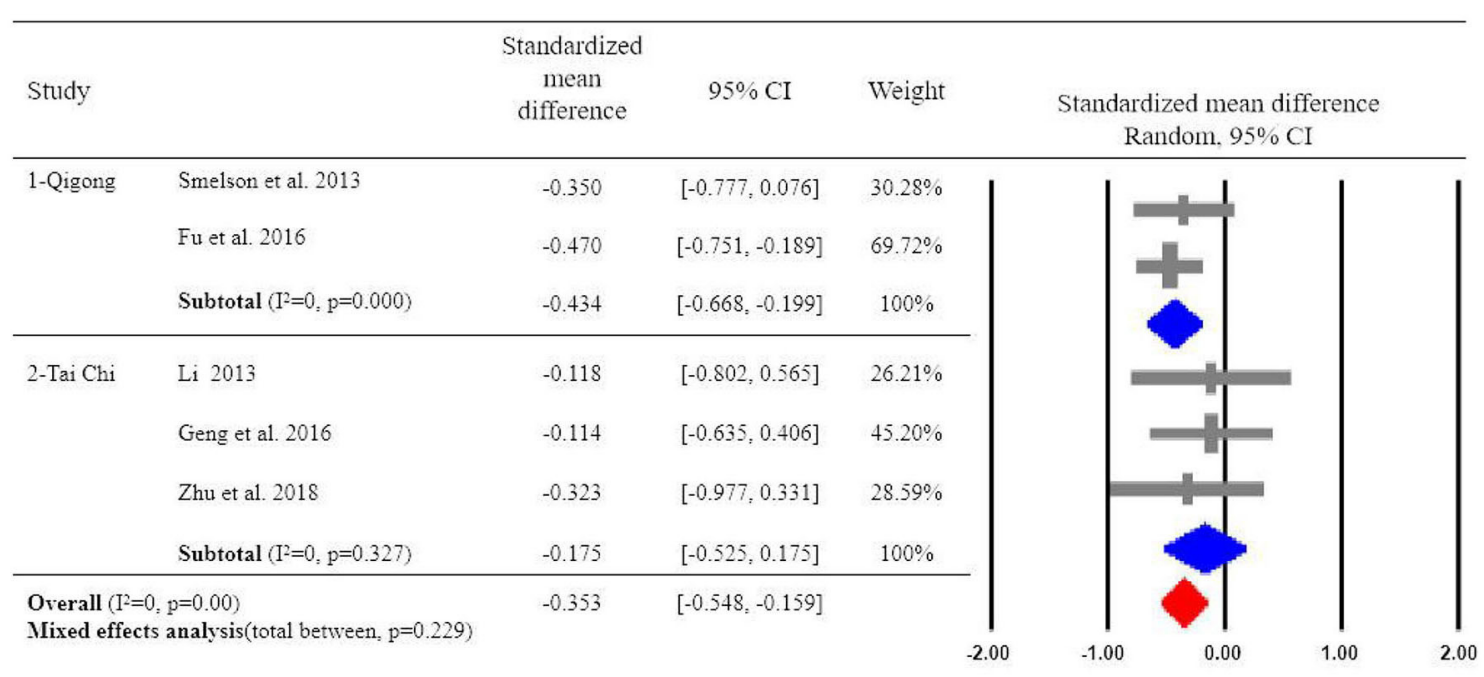

B

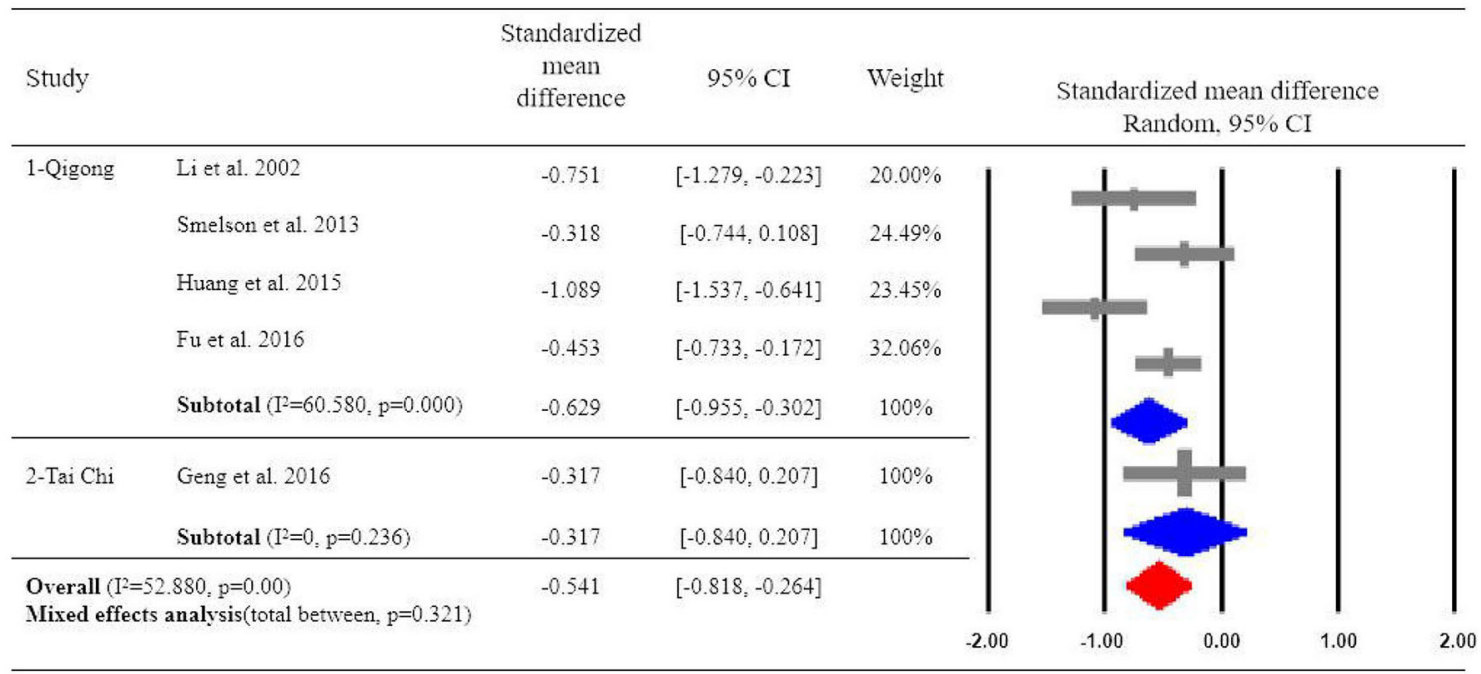

C

\begin{tabular}{|c|c|c|c|c|c|c|}
\hline Study & & $\begin{array}{c}\text { Standardized } \\
\text { mean } \\
\text { difference }\end{array}$ & $95 \% \mathrm{CI}$ & Weight & $\begin{array}{c}\text { Standardized mean difference } \\
\text { Random, } 95 \% \text { CI }\end{array}$ & \\
\hline \multirow[t]{2}{*}{ 1-Qigong } & Li et al. 2018 & 0.750 & {$[0.463,1.036]$} & $100 \%$ & 1 & 1 \\
\hline & Subtotal $\left(\mathrm{I}^{2}=0, \mathrm{p}=0.000\right)$ & 0.750 & {$[0.463,1.036]$} & $100 \%$ & & \\
\hline \multirow[t]{3}{*}{ 2-Tai Chi } & Zhu et al. $2016 \mathrm{a}$ & 0.402 & {$[-0.254,1.058]$} & $38.72 \%$ & & \\
\hline & Zhu et al. $2016 \mathrm{~b}$ & 0.590 & {$[0.068,1.111]$} & $61.28 \%$ & & \\
\hline & Subtotal $\left(\mathrm{I}^{2}=0, \mathrm{p}=0.013\right)$ & 0.517 & {$[0.109,0.925]$} & $100 \%$ & & \\
\hline \multirow{2}{*}{\multicolumn{2}{|c|}{$\begin{array}{l}\text { Overall }\left(\mathrm{I}^{2}=0, \mathrm{p}=0.000\right) \\
\text { Mixed effects analysis(total between, } \mathrm{p}=0.361)\end{array}$}} & 0.673 & {$[0.438,0.907]$} & & & \\
\hline & & & & -2.00 & -1.00 & 2.00 \\
\hline
\end{tabular}

FIGURE 2 | Continued 


\begin{tabular}{|c|c|c|c|c|c|c|c|}
\hline Study & & $\begin{array}{c}\text { Standardized } \\
\text { mean } \\
\text { difference }\end{array}$ & $95 \% \mathrm{CI}$ & Weight & \multicolumn{3}{|c|}{$\begin{array}{c}\text { Standardized mean difference } \\
\text { Random, } 95 \% \mathrm{CI}\end{array}$} \\
\hline \multirow[t]{2}{*}{ 1-Qigong } & Fu et al. 2016 & -0.433 & {$[-0.713,-0.152]$} & $100 \%$ & & 1 & 1 \\
\hline & Subtotal $\left(I^{2}=0, p=0.002\right)$ & -0.433 & {$[-0.713,-0.152]$} & $100 \%$ & & & \\
\hline \multirow[t]{2}{*}{ 2-Tai Chi } & Zhu et al. 2018 & -0.053 & {$[-0.705,0.598]$} & $100 \%$ & & & \\
\hline & Subtotal $\left(I^{2}=0, p=0.872\right)$ & -0.053 & {$[-0.705,0.598]$} & $100 \%$ & & & \\
\hline \multirow{2}{*}{\multicolumn{2}{|c|}{$\begin{array}{l}\text { Overall }\left(I^{2}=8.998, p=0.004\right) \\
\text { Mixed effects analysis(total between, } p=0.295 \text { ) }\end{array}$}} & -0.373 & {$[-0.631,-0.116]$} & & & & \\
\hline & & & & -2.00 & -1.00 & 1.00 & 2.00 \\
\hline
\end{tabular}

FIGURE 2 | (A) Effects of Qigong or Tai Chi on depressive symptoms. (B) Effects of Qigong or Tai Chi on anxiety symptoms. (C) Effects of Qigong or Tai Chi on Quality of life scale for drug addicts. (D) Effects of Qigong or Tai Chi on Pittsburg Sleep Quality Index.

exercise can improve depression, anxiety, quality of life, and sleep quality. The subgroup analyses showed that qigong exercise outperformed tai chi on alleviating addiction-related symptoms.

We found that qigong and tai chi exercise produced a significant effect on improvement of depression and anxiety in patients with drug addiction. It is probably because improvements in general physical health or reductions in chronic disease symptoms may contribute to improvements in patients' mental health. Although subgroup analysis found that qigong is significantly associated with improved anxiety symptoms, there exists high heterogeneity among the included of studies $\left(I^{2}=\right.$ 60.580). This may be due to the different measurement tools and interventions used in the study, as well as the intervention periods. However, in the subgroup analysis of tai chi, the effects of tai chi exercise on patient depression and anxiety were not significant, which may be related to the following aspects. First, compared to tai chi, qigong may focus more on the flow of "qi" (e.g., breath and intention) in the body and the effects from it. According to Chinese medical philosophy, qigong believes that the human body is a "small universe" and that diseases occur because the circulation of "qi" (vital energy) in the human body is blocked. Qigong is considered to be a method to achieve the harmonious flow of vital energy in the human body and to regulate the functional activities of the meridians and internal organs $(22,33,34,56-58)$. Qigong exercises always require the practitioner to integrate the body, breath, and the mind (spirit), whether it be dynamic or static qigong, and consciously guiding the flow of "qi" in the body is the most crucial and core element of the practice $(59,60)$. Secondly, qigong has a much longer history than tai chi in promoting the development of human mental health. "Promoting healthy development of the body" has always been the unchanging function and principle of qigong. In contrast, tai chi originally existed as a martial art, consisting of movements with offensive and defensive functions. Only with cultural changes did it evolve into many gentler styles, and its function or intention gradually tilted toward mental health promotion (59). Thirdly, the small number of studies available on tai chi exercise (four papers on qigong exercise, but only one on tai chi exercise. Finally, from the available evidence and the overall results of the two qigong and tai chi subgroups, it appears that qigong and tai chi exercises are potentially beneficial in improving patients' depression and anxiety symptoms, but more rigorous studies are needed in the future to verify this.

Compared to depression and anxiety, less research focused on quality of life in drug addiction patients. Quality of life reflects the patient's perception of personal health and life satisfaction over time (61). Research in this area suggests that addiction can affect various aspects of daily functioning, including physical health $(62,63)$, and social functioning (64). Individuals with drug addiction tend to have a lower level of quality of life compared to the general population (65-67). Based on our findings, both qigong and tai chi interventions showed significant improvement in the quality of life of drug addiction patients. Specifically, patients showed significant improvements in somatic functioning, psychological functioning, social functioning, and symptoms/side effects after qigong or tai chi interventions, which are consistent with the results of previous studies $(68,69)$.

Compared to the outcome variables mentioned above, from the studies included in this paper, it is evident that researchers have paid less attention to sleep quality, heroin dependence protracted withdrawal symptoms, and cocaine craving symptoms. However, a large body of research $(43,70-74)$ shows that these three factors are also very important indicators for drug addiction patients, and there are reviews that have confirmed qigong or tai chi interventions to be effective as well $(6,15,43,75)$. Although our study also found similar significant effects, the number of articles was too small to classify our results as robust. More attention and research could be devoted to this research in the future, as the improvement of different symptoms is always beneficial for the physical and mental health of drug addiction patients.

This review has several potential limitations. First, the quality included studies was relatively low (e.g., two RCTs), making it 
difficult to judge the effectiveness and provide clear conclusions about qigong and tai chi interventions. Second, only 11 articles were included in the meta-analysis, making it difficult to have reliable results. Third, some of the patients included in the articles were provided a combination of medication and qigong and tai chi interventions, making it difficult for us to determine whether the results were due to the efficacy of qigong itself or the synergistic effect of the medications and the exercises. Fourth, the intervention designs, selection processes, and measurements of outcome variables varied considerably, which could lead to some uncertainty in our results. Last but not the least, subgroup analysis for sex comparison was not allowed in this meta-analysis due to large gender inequality of these included studies as well as the absence of independent results across gender in those trials with both males and females.

\section{CONCLUSION}

This meta-analysis suggests that qigong and tai chi can be effective in improving depression, anxiety, and quality of life in patients with drug addiction, validating their use as adjunctive treatments for depression, anxiety, and quality of life in drug users. However, the effectiveness of qigong and tai chi in improving sleep quality, heroin dependence protracted

\section{REFERENCES}

1. UNODC. (2019). World Drug Report 2019: 35 Million People Worldwide Suffer From Drug Use Disorders While Only 1 in 7 People Receive Treatment.

2. Hester R, Lubman DI, Yücel M. The role of executive control in human drug addiction. Curr Top Behav Neurosci. (2010) 3:301-318. doi: 10.1007/7854_2009_28

3. Nestler EJ. Molecular basis of long-term plasticity underlying addiction. Nat Rev Neurosci. (2001) 2:19-28. doi: 10.1038/35053570

4. Cargiulo, T. (2007). Understanding the health impact of alcohol dependence. Am J Health Syst Pharm. 5(Suppl. 3):S5-11. doi: 10.2146/ajhp0 60647

5. Degenhardt L, Hall W. Extent of illicit drug use and dependence, and their contribution to the global burden of disease. Lancet. (2012) 9810:5570. doi: 10.1016/S0140-6736(11)61138-0

6. Wang F, Eun-Kyoung Lee O, Feng F, Vitiello MV, Wang W, Benson H, et al. The effect of meditative movement on sleep quality: a systematic review. Sleep Med Rev. (2016) 30:43-52. doi: 10.1016/j.smrv.2015.12.001

7. Grant BF, Goldstein RB, Saha TD, Chou SP, Jung J, Zhang H, et al. Epidemiology of DSM-5 alcohol use disorder: results from the national epidemiologic survey on alcohol and related conditions III. JAMA Psychiatry. (2015) 8:757-66. doi: 10.1001/jamapsychiatry.2015.0584

8. Tan JH, Lu XQ, Duan JL, Liu KC, Yu XQ. A survey of the psychological status of 86 cases of drug addicts in Xiamen. Chin Med Cases. (2005) 9:38-9. doi: 10.3969/j.issn.1672-2566.2005.09.025

9. Deng Q, Tang Q, Schottenfeld RS, Hao W, Chawarski MC. Drug use in rural China: a preliminary investigation in Hunan Province. Addiction. (2012) 3:610-3. doi: 10.1111/j.1360-0443.2011.03648.x

10. World Health Organization. (2011). Global Status Report on Alcohol and Health, 2014: World Health Organization. Washington, DC: World Health Organization.

11. Wu N, Li J. Biological entity of drug addiction. Chin J Drug Abuse Prev Treat. (2013) 1:1-6. doi: 10.3969/j.issn.1006-902X.2013.01.001

12. Diaper AM, Law FD, Melichar JK. Pharmacological strategies for detoxification. Br J Clin Pharmacol. (2014) 2:302-14. doi: 10.1111/bcp.12245 withdrawal symptoms; cocaine craving in these patients is unclear due to the paucity of the literature, and more studies in this area are needed in the future to validate their efficacy and effects.

\section{DATA AVAILABILITY STATEMENT}

The original contributions presented in the study are included in the article/supplementary material, further inquiries can be directed to the corresponding author.

\section{AUTHOR CONTRIBUTIONS}

JC: conceptualization, formal analysis, and writing-original draft. FL: screening. XL: screening and formal analysis. RL: formal analysis and writing-review and editing. XC and HZ: writing-review and editing. All authors contributed to the article and approved the submitted version.

\section{FUNDING}

This work was partially supported by a grant from the National Social Science Fund of China (Grant no. 13\&ZD140).

13. Veilleux JC, Colvin PJ, Anderson J, York C, Heinz AJ. A review of opioid dependence treatment: pharmacological and psychosocial interventions to treat opioid addiction. Clin Psychol Rev. (2010) 2:155-66. doi: 10.1016/j.cpr.2009.10.006

14. Zhu $\mathrm{H}, \mathrm{Wu}$ LT. National trends and characteristics of inpatient detoxification for drug use disorders in the United States. BMC Public Health. (2018) 1:1073. doi: 10.1186/s12889-018-5982-8

15. Li DX, Zhuang XY, Zhang YP, Guo H, Wang Z, Zhang Q, et al. Effects of Tai Chi on the protracted abstinence syndrome: a time trial analysis. Am J Chin Med. (2013) 1:43-57. doi: 10.1142/S0192415X13500043

16. Allsop DJ, Norberg MM, Copeland J, Fu S, Budney AJ. The cannabis withdrawal scale development: patterns and predictors of cannabis withdrawal and distress. Drug Alcohol Depend. (2011) 119:123-9. doi: 10.1016/j.drugalcdep.2011.06.003

17. Herrmann ES, Weerts EM, Vandrey R. Sex differences in cannabis withdrawal symptoms among treatment-seeking cannabis users. Exp Clin Psychopharmacol. (2015) 6:415-21. doi: 10.1037/pha0000053

18. Levin KH, Copersino ML, Heishman SJ, Liu F, Kelly DL, Boggs DL, et al. Cannabis withdrawal symptoms in non-treatmentseeking adult cannabis smokers. Drug Alcohol Depend. (2010) 111:120-7. doi: 10.1016/j.drugalcdep.2010.04.010

19. Panlilio LV, Goldberg SR, Justinova Z. Cannabinoid abuse and addiction: clinical and preclinical findings. Clin Pharmacol Ther. (2015) 6:61627. doi: $10.1002 /$ cpt.118

20. Li W, Howard MO, Garland EL, McGovern P, Lazar M. Mindfulness treatment for substance misuse: a systematic review and meta-analysis. J Subst Abuse Treat. (2017) 75:62-96. doi: 10.1016/j.jsat.2017.01.008

21. Liu F, Cui J, Liu X, Chen KW, Chen X, Li R. The effect of tai chi and Qigong exercise on depression and anxiety of individuals with substance use disorders: a systematic review and meta-analysis. BMC Complement Med Ther. (2020) 1:161. doi: 10.1186/s12906-020-02967-8

22. Wang CW, Chan CH, Ho RT, Chan JS, Ng SM, Chan CL. Managing stress and anxiety through qigong exercise in healthy adults: a systematic review and meta-analysis of randomized controlled trials. BMC Complement Altern Med. (2014) 14:8. doi: 10.1186/1472-6882-14-8 
23. Brown RA, Abrantes AM, Read JP, Marcus BH, Jakicic J, Strong DR, et al. A pilot study of aerobic exercise as an adjunctive treatment for drug dependence. Ment Health Phys Act. (2010) 1:27-34. doi: 10.1016/j.mhpa.2010.03.001

24. Buchowski MS, Meade NN, Charboneau E, Park S, Dietrich MS, Cowan $\mathrm{RL}$, et al. Aerobic exercise training reduces cannabis craving and use in non-treatment seeking cannabis-dependent adults. PLoS ONE. (2011) 3:e17465. doi: 10.1371/journal.pone.0017465

25. Bardo MT, Compton WM. Does physical activity protect against drug abuse vulnerability? Drug Alcohol Depend. (2015) 153:3-13. doi: 10.1016/j.drugalcdep.2015.05.037

26. Brellenthin AG, Lee DC. Physical activity and the development of substance use disorders: current knowledge and future directions. Prog Prev Med (New York, NY). (2018) 3:e0018. doi: 10.1097/pp9.0000000000000018

27. Giménez-Meseguer J, Tortosa-Martínez J, Cortell-Tormo JM. The benefits of physical exercise on mental disorders and quality of life in substance use disorders patients. Systematic review and meta-analysis. Int J Environ Res Public Health. (2020) 17:3680. doi: 10.3390/ijerph17103680

28. Cohen K. The Way of Qigong = [Chi kung chi tao]: The Art and Science of Chinese Energy Healing. New York, NY: Ballantine Books (1997).

29. NIH. (2013). Mind-Body Medicine Practices in Complementary and Alternative Medicine. Available online at: https://report.nih.gov/ biennialreport1213/chronic_pain_and_palliative_care.html (accessed October 2020).

30. Larkey L, Jahnke R, Etnier J, Gonzalez J. Meditative movement as a category of exercise: implications for research. J Phys Act Health. (2009) 6:2308. doi: 10.1123/jpah.6.2.230

31. Jahnke R, Larkey L, Rogers C, Etnier J, Lin F. A comprehensive review of health benefits of qigong and tai chi. Am J Health Promot. (2010) 6:e1e25. doi: 10.4278/ajhp.081013-LIT-248

32. Wang C, Bannuru R, Ramel J, Kupelnick B, Scott T, Schmid CH. Tai Chi on psychological well-being: systematic review and meta-analysis. $B M C$ Complement Altern Med. (2010) 10:23. doi: 10.1186/1472-6882-10-23

33. Wang D, Wang Y, Wang Y, Li R, Zhou C. Impact of physical exercise on substance use disorders: a meta-analysis. PLoS ONE. (2014) 10:e110728. doi: 10.1371/journal.pone.0110728

34. Wang J, Zhang Q, Zhao L, Li D, Fu Z, Liang L. Down-regulation of PPAR $\alpha$ in the spinal cord contributes to augmented peripheral inflammation and inflammatory hyperalgesia in diet-induced obese rats. Neuroscience. (2014) 278:165-78. doi: 10.1016/j.neuroscience.2014.07.071

35. So W, Cai S, Yau SY, Tsang H. The neurophysiological and psychological mechanisms of Qigong as a treatment for depression: a systematic review and meta-analysis. Front Psychiatry. (2019) 10:820. doi: 10.3389/fpsyt.2019.00820

36. Chan CL, Wang CW, Ho RT, Ng SM, Chan JS, Ziea ET, et al. A systematic review of the effectiveness of qigong exercise in supportive cancer care. Support Care Cancer. (2012) 6:1121-33. doi: 10.1007/s00520-011-1378-3

37. Chen KW, Comerford A, Shinnick P, Ziedonis DM. Introducing qigong meditation into residential addiction treatment: a pilot study where gender makes a difference. J Altern Complement Med. (2010) 8:87582. doi: 10.1089/acm.2009.0443

38. Colledge F, Vogel M, Dürsteler-Macfarland K, Strom J, Schoen S, Pühse $\mathrm{U}$, et al. A pilot randomized trial of exercise as adjunct therapy in a heroin-assisted treatment setting. J Subst Abuse Treat. (2017) 76:4957. doi: 10.1016/j.jsat.2017.01.012

39. Oh CU, Kim NC. Effects of T'ai Chi on serotonin, nicotine dependency, depression, and anger in hospitalized alcohol-dependent patients. J Altern Complement Med. (2016) 12:957-63. doi: 10.1089/acm.201 6.0246

40. Peng XL, Lin H, Cao JP, Su W, Zhang LD, Song XG. Observation on the regulation of abnormal emotions of compulsory drug addicts by Baduanjin gongfu. J Chifeng Coll (Natural Science Edition). (2018) 11:65-7. doi: 10.13398/j.cnki.issn1673-260x.2018.11.019

41. Fu GJ, Huang SJ, Tang CQ, Liu Y, Gao YL, Cao JP, et al. Effect of Wuqinxi on emotion in patients abstaining from drugs. J Anhui Univ Trad Chin Med. (2016) 5:26-9. doi: 10.3968/j.issn.2095-7246.2016.05.008

42. Geng JJ, Zhu D, Xu D. Effectiveness of Taiji rehabilitation exercises on the rehabilitation of female drug addicts in compulsory isolation. Chin J Sports Medicine. (2016) 11:1048-51. doi: 10.16038/j.1000-6710.2016. 11.011
43. Smelson D, Chen KW, Ziedonis D, Andes K, Lennox A, Callahan L, et al. A pilot study of Qigong for reducing cocaine craving early in recovery. J Altern Complement Med. (2013) 2:97-101. doi: 10.1089/acm.2012.0052

44. Zhu D, Dai G, Xu D, Xu X, Geng J, Zhu W, et al. Long-term effects of Tai Chi Intervention on sleep and mental health of female individuals with dependence on amphetamine-type stimulants. Front Psychol. (2018) 9:1476. doi: 10.3389/fpsyg.2018.01476

45. Huang XL, Wu SP, Xu HZ. Clinical observation on the practice of Badaanjin with methadone to improve anxiety symptoms in heroindependent patients. Shenzhen J Integr Chin Western Med. (2015) 13:98-9. doi: 10.16458/J.cnki.1007-0893.2015.13.052

46. Huang XL, Xu HZ, Wu SP. A clinical study on the practice of Badaanjin to intervene in heroin dependence auditory withdrawal symptoms. Clin Med Eng. (2017) 12:1679-80. doi: 10.3969/j.issn.1674-4659.2017.12.1679

47. Li WT, Han QL, Luo PS, Shi NN. Effect of TCM guide rehabilitation training on life quality of drug addicts. Gansu Med J. (2018) 11:977-9. doi: 10.15975/j.cnki.gsyy.2018.11.006

48. Zhu D, Xu D, Dai GB, Geng JJ. An empirical study of Tai Chi rehabilitation exercises on physical and psychological rehabilitation of synthetic drug addicts. Chin J Drug Depend. (2016) 3:284-90. doi: 10.13936/j.cnki.cjdd1992.2016.03.008

49. Zhu D, Xu D, Dai G, Wang F, Xu X, Zhou D. Beneficial effects of Tai Chi for amphetamine-type stimulant dependence: a pilot study. Am J Drug Alcohol Abuse. (2016) 4:469-78. doi: 10.3109/00952990.2016.1153646

50. Wang WC, Zhang AL, Rasmussen B, Lin LW, Dunning T, Kang SW, et al. The effect of Tai Chi on psychosocial well-being: a systematic review of randomized controlled trials. J Acupunct Meridian Stud. (2009) 3:17181. doi: 10.1016/S2005-2901(09)60052-2

51. Orwin RG. A Fail-Safe N for effect size in meta-analysis. J Educ Stats. (1983) 2:157-9. doi: 10.2307/1164923

52. Boutron I, Moher D, Tugwell P, Giraudeau B, Poiraudeau S, Nizard R, et al. A checklist to evaluate a report of a nonpharmacological trial (CLEAR NPT) was developed using consensus. J Clin Epidemiol. (2005) 12:123340. doi: 10.1016/j.jclinepi.2005.05.004

53. Chen KW, Berger CC, Manheimer E, Forde D, Magidson J, Dachman L, et al. Meditative therapies for reducing anxiety: a systematic review and meta-analysis of randomized controlled trials. Depress Anxiety. (2012) 7:54562. doi: $10.1002 /$ da. 21964

54. Higgins JP, Thompson SG, Deeks JJ, Altman DG. Measuring inconsistency in meta-analyses. BMJ. (2003) 7414:557-60. doi: 10.1136/bmj.327.7414.557

55. Li M, Chen K, Mo Z. Use of qigong therapy in the detoxification of heroin addicts. Altern Ther Health Med. (2002) 1:56-59.

56. Chang PS, Knobf MT, Funk M, Oh B. Feasibility and acceptability of Qigong exercise in community-dwelling older adults in the United States. J Altern Complement Med. (2018) 1:48-54. doi: 10.1089/acm.2017.0096

57. McCaffrey R, Fowler NL. Qigong practice: a pathway to health and healing. Holist Nurs Pract. (2003) 2:110-6. doi: 10.1097/00004650-20030300000006

58. Tsang HW, Fung KM. A review on neurobiological and psychological mechanisms underlying the anti-depressive effect of qigong exercise. J Health Psychol. (2008) 7:857-63. doi: 10.1177/1359105308095057

59. Liu X, Clark J, Siskind D, Williams GM, Byrne G, Yang JL, et al. A systematic review and meta-analysis of the effects of Qigong and Tai Chi for depressive symptoms. Complement Ther Med. (2015) 4:51634. doi: 10.1016/j.ctim.2015.05.001

60. Zhang YP, Hu RX, Han M, Lai BY, Liang SB, Chen BJ, et al. Evidence base of clinical studies on Qi Gong: a bibliometric analysis. Complement Ther Med. (2020) 102392. doi: 10.1016/j.ctim.2020.102392

61. Abbott R, Lavretsky H. Tai Chi and Qigong for the treatment and prevention of mental disorders. Psychiatr Clin North Am. (2013) 1:10919. doi: 10.1016/j.psc.2013.01.011

62. Dalen E, Holmen J, Nordahl HM. Somatic health of patients at an outpatient clinic for substance abuse. Tidsskr Nor Laegeforen. (2015) 2:12731. doi: 10.4045/tidsskr.13.0801

63. Fischer JA, Conrad S, Clavarino AM, Kemp R, Najman JM. Quality of life of people who inject drugs: characteristics and comparisons with other population samples. Qual Life Res. (2013) 8:2113-21. doi: 10.1007/s11136-013-0350-8 
64. Longabaugh R, Mattson ME, Connors GJ, Cooney NL. Quality of life as an outcome variable in alcoholism treatment research. J Stud Alcohol Suppl. (1994) 119-29. doi: 10.15288/jsas.1994.s12.119

65. Morgan TJ, Morgenstern J, Blanchard KA, Labouvie E, Bux DA. Health-related quality of life for adults participating in outpatient substance abuse treatment. Am J Addict. (2003) 3:198-210. doi: 10.1111/j.1521-0391.2003.tb00648.x

66. Smith KW, Larson MJ. Quality of life assessments by adult substance abusers receiving publicly funded treatment in Massachusetts. Am J Drug Alcohol Abuse. (2003) 2:323-35. doi: 10.1081/ADA-120020517

67. Stein MD, Mulvey KP, Plough A, Samet JH. The functioning and well being of persons who seek treatment for drug and alcohol use. J Subst Abuse. (1998) 1:75-84. doi: 10.1016/S0899-3289(99)80142-4

68. Wan C, Fang J, Jiang R, Shen J, Jiang D, Tu X, et al. Development and validation of a quality of life instrument for patients with drug dependence: comparisons with SF-36 and WHOQOL-100. Int J Nurs Stud. (2011) 9:108095. doi: 10.1016/j.ijnurstu.2011.02.012

69. Zhou K, Zhuang G, Zhang H, Liang P, Yin J, Kou L, et al. Psychometrics of the Short Form 36 health survey version 2 (SF-36v2) and the Quality of Life Scale for Drug Addicts (QOL-DAv20) in Chinese mainland patients with methadone maintenance treatment. PLoS One. (2013) 11:e79828. doi: 10.1371/journal.pone.0079828

70. Bao YP, Qiu Y, Yan SY, Jia ZJ, Li SX, Lian Z, et al. Pattern of drug use and depressive symptoms among amphetamine type stimulants users in Beijing and Guangdong province, China. PLoS ONE. (2013) 4:e60544. doi: 10.1371/journal.pone.0060544

71. Lipinska G, Timol R, Thomas KG. The implications of sleep disruption for cognitive and affective processing in methamphetamine abuse. Med Hypotheses. (2015) 6:914-21. doi: 10.1016/j.mehy.2015.09.010

72. Mahoney JJ 3rd, De La Garza R 2nd, Jackson BJ, Verrico CD, Ho A, Iqbal T, Newton TF. The relationship between sleep and drug use characteristics in participants with cocaine or methamphetamine use disorders. Psychiatry Res. (2014) 2:367-71. doi: 10.1016/j.psychres.2014.05.026

73. Putnins SI, Griffin ML, Fitzmaurice GM, Dodd DR, Weiss RD. Poor sleep at baseline predicts worse mood outcomes in patients with co-occurring bipolar disorder and substance dependence. J Clin Psychiatry. (2012) 5:7038. doi: 10.4088/JCP.11m07007

74. Tang J, Liao Y, He H, Deng Q, Zhang G, Qi C, et al. Sleeping problems in Chinese illicit drug dependent subjects. BMC Psychiatry. (2015) 15:28. doi: 10.1186/s12888-015-0409-x

75. Irwin MR, Olmstead R, Motivala SJ. Improving sleep quality in older adults with moderate sleep complaints: a randomized controlled trial of Tai Chi Chih. Sleep. (2008) 7:1001-8.

Conflict of Interest: The authors declare that the research was conducted in the absence of any commercial or financial relationships that could be construed as a potential conflict of interest.

Publisher's Note: All claims expressed in this article are solely those of the authors and do not necessarily represent those of their affiliated organizations, or those of the publisher, the editors and the reviewers. Any product that may be evaluated in this article, or claim that may be made by its manufacturer, is not guaranteed or endorsed by the publisher.

Copyright (C) $2022 \mathrm{Cui}$, Liu, Liu, Li, Chen and Zeng. This is an open-access article distributed under the terms of the Creative Commons Attribution License (CC BY). The use, distribution or reproduction in other forums is permitted, provided the original author(s) and the copyright owner(s) are credited and that the original publication in this journal is cited, in accordance with accepted academic practice. No use, distribution or reproduction is permitted which does not comply with these terms. 